\title{
Further refinement of the Usher 2A locus at $1 \mathrm{q} 41$
}

\author{
David A R Bessant, Annette M Payne, Catherine Plant, Alan C Bird, \\ Shomi S Bhattacharya
}

\begin{abstract}
Usher syndrome (USH) is characterised by congenital sensorineural hearing loss and progressive pigmentary retinopathy. All three subtypes (USH1, USH2, and USH3) are inherited as recessive traits. People with Usher type 2 (USH2) have normal vestibular responses and moderate to severe hearing loss.

These syndromes have been found to be genetically heterogeneous, with a single locus for USH2 at 1q41 (USH2A), six loci for USH1, and one for USH3. Some USH2 families have been excluded from the 1q41 locus suggesting that a second, as yet unidentified, locus (USH2B) must exist. Linkage studies suggest that around $\mathbf{9 0 \%}$ of USH2 families are USH2A.
\end{abstract}

Four USH2 families were analysed for linkage to markers flanking the USH2A locus. In one of these families a recombination event was observed in an affected subject which excludes the USH2A gene from proximal to the marker AFM143XF10 and defines this as the new centromeric flanking marker for the USH2A locus. A further recombination event in another patient from this family confirmed AFM144XF2 as the telomeric flanking marker.

The interval between these polymorphic markers is estimated to be $400 \mathrm{~kb}$. This region is completely contained in each of three YACs from the CEPH library: $867 \mathrm{g9}$, 919h3, and $848 \mathrm{~b} 9$. This refinement more than halves the critical genetic interval and will greatly facilitate positional cloning of the USH2A gene. $(\mathcal{M}$ Med Genet 1998;35:773-774)

Keywords: Usher syndrome; retinitis pigmentosa; genetics

Department of

Molecular Genetics,

Institute of

Ophthalmology,

University College

London, London

EC1V 9EL, UK

D A R Bessant

A M Payne

S S Bhattacharya

Moorfields Eye

Hospital, London, UK

D A R Bessant

C Plant

A C Bird

Correspondence to:

Professor Bhattacharya.

Received 2 December 1997 Revised version accepted for publication 5 March 1998
(USH1) have profound sensorineural deafness and absent vestibular function. They do not benefit from traditional hearing aids and typically communicate by sign language. Sub- jects with Usher type 2 (USH2) have normal vestibular responses and moderate to severe sensorineural hearing loss, while those with Usher III experience progressive hearing loss.

These syndromes have been found to be genetically heterogeneous with a total of nine genetic loci now reported. The gene MYO7A, located at 11q13, has been shown to be responsible for cases of Usher $1 \mathrm{~B} .{ }^{4}$ There are five additional loci for USH1, at $14 \mathrm{q} 32$ (USH1A), ${ }^{5}$ at $11 \mathrm{p} 13$ (USH1C), ${ }^{6}$ at $10 \mathrm{q}$ (USH1D), ${ }^{7}$ 21q (USH1E), ${ }^{8}$ and on chromosome 10 (USH1F). ${ }^{9}$ There is a single locus for $\mathrm{USH} 2$ at $1 \mathrm{q} 41$ (USH2A). ${ }^{10} \mathrm{USH} 3$ has been linked to $3 \mathrm{q} 25 .{ }^{11}$

The original localisation of $\mathrm{USH} 2 \mathrm{~A}^{10}$ was to a $14.8 \mathrm{cM}$ interval on $1 \mathrm{q} 41$ and this was later refined to a $2.1 \mathrm{cM}$ region between markers D1S237 and D1S229. ${ }^{12}$ The construction of a yeast artificial chromosome (YAC) contig across this region, and the detection of recombination events in two separate families, permitted further refinement to a physical distance of $1.0 \mathrm{Mb}$ between markers D1S474 and AFM144XF2. ${ }^{13}$

Pieke-Dahl et al ${ }^{14}$ studied linkage to $1 \mathrm{q} 41$ markers in 29 Dutch families with clinical manifestations of USH2. Linkage to $1 \mathrm{q} 41$ was shown in 26 families indicating that around $90 \%$ of these families have USH2A. Several of the remaining families were excluded from the $1 \mathrm{q} 41$ locus suggesting that a second, as yet unidentified, locus (USH2B) must exist.

In the present study haplotype analysis of an inbred USH2A family has allowed us to determine a new centromeric flanking marker for this disorder and confirm AFM144XF2 as the telomeric flanking marker.

After gaining informed consent, genomic DNA was prepared from peripheral blood obtained from four unrelated USH2 families. Three of these were pedigrees from the Moorfields Eye Hospital retinal dystrophy register and one was ascertained in Pakistan. The patients in pedigree USH2(4) are of Sephardic Jewish extraction. Their parents, now dead, were uncle and niece. The three affected subjects were examined by two of the authors (DARB and ACB). All three had moderate congenital sensorineural hearing loss, without vestibular dysfunction, and had developed typical symptoms and signs of retinitis pigmentosa.

Non-radioactive $P C R$ was performed in a 10 $\mu$ l reaction with $300 \mathrm{ng}$ of genomic DNA, 10 pmol of each primer, $200 \mu \mathrm{mol} / 1 \mathrm{dNTPs}, 1.5$ $\mathrm{mmol} / \mathrm{l} \mathrm{MgCl}_{2}$, and 1 unit of Taq DNA polymerase (Biotaq) in buffer provided by the manufacturer. A three stage PCR consisting of 35 cycles at $94^{\circ} \mathrm{C}, 50-62^{\circ} \mathrm{C}$, and $72^{\circ} \mathrm{C}$, each for 


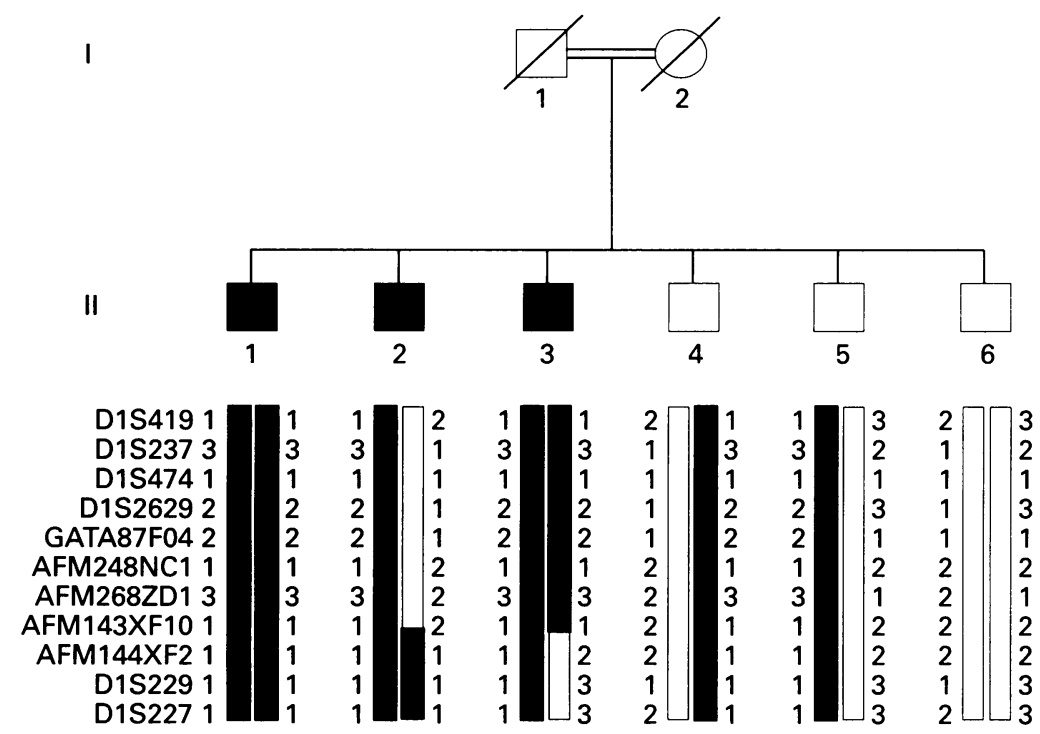

Figure 1 Pedigree of family USH2(4) showing haplotypes for the polymorphic markers in the critical interval for USH2 on 1q41. Marker order was determined from the Généthon sex averaged genetic map ${ }^{15}$ and the Whitehead Institute YAC contig WC1-19

(http://www-genome.wi.mit.edu). Recombination events in affected subjects II. 2 and II. 3 define AFM143XF10 and AFM144XF2 as the flanking markers for the USH2 locus. Subject II.1 is homozygous for all markers spanning this region. (Affected males are denoted by solid squares.)

one minute, was used. The amplified products were then separated by electrophoresis on $6-8 \%$ non-denaturing polyacrylamide gels (Protogel, National Diagnostics) and stained with ethidium bromide.

All four families were analysed for polymorphic markers flanking the known USH2A locus (D1S419, D1S237, D1S229, D1S227). In three families, including the large Pakistani pedigree, evidence of linkage without any informative recombination events was obtained for these markers (data not shown). In the family USH2(4), however, both a centromeric and a telomeric recombination event were observed in different subjects (fig 1).

This family was then analysed further using polymorphic markers located within the USH $2 \mathrm{~A}$ critical region. The location and order of these markers was determined from the Généthon sex averaged genetic map ${ }^{15}$ and the Whitehead Institute YAC contig WC1-19 (http://www-genome.wi.mit.edu). A recombination event observed in the affected subject II. 2 excludes the USH2A gene from proximal to AFM143XF10 and defines this as the new centromeric flanking marker for the USH2A locus. A further recombination event in patient II. 3 confirms AFM144XF2 as the telomeric flanking marker. The remaining affected subject (II.1) was homozygous for all markers spanning this region.

While it is unusual for two recombination events to occur in such close proximity in a small sibship, it remains highly likely that the observed results represent a further refinement of the USH2A locus rather than an exclusion of this family from that locus.

The interval between AFM143XF10 and AFM144XF2 is estimated to be $400 \mathrm{~kb}$ (W Kimberling, personal communication). Based on data both from the Whitehead contig WC1-19 and the contig published by Sumegi et $a l,{ }^{13}$ this region is covered by 11 YACs from the CEPH library : 867g9, 919h3, 848b9, 873a8, $836 \mathrm{c} 7,763 \mathrm{~d} 7,762 \mathrm{a} 6,945 \mathrm{f} 7,798 \mathrm{~b} 4,785 \mathrm{~h} 4$, and $841 \mathrm{~g} 2$. The critical genetic interval is completely contained on each of three of these YACs $(867 \mathrm{~g} 9,919 \mathrm{~h} 3$, and $848 \mathrm{~b} 9)$.

On the contig WC1-19 there are three STSs (WI-3484, WI-3128, and WI-9496) within this interval, but no polymorphic markers that can be used in further refinement. At least four STSs on WC1-19 have been excluded by this refinement. WI-3484 and WI-3128 have no significant homology at the nucleotide level to any known genes or human CDNA sequences. WI-9496 is a partial cDNA (NCBI Entrez accession No Z39073) from a normalised infant brain library. Sequence database searching indicates homology between WI-9496 and several other human cDNA sequences including a human retina clone (Entrez accession No W28993)

This refinement has more than halved the remaining genetic critical interval for this locus and will greatly facilitate the positional cloning of the USH $2 \mathrm{~A}$ gene.

Drs David A R Bessant and Annette M Payne are supported by the Medical Research Council of the UK (grant No G9301094). We would like to thank Professor S Qasim Mehd at the Dr A Q Khan Research Laboratories, Biomedical and Genetic Engineering Division, Islamabad, Pakistan, for providing patient samples for this study.

1 Usher J. The Bowman lecture: on a few hereditary eye afflictions. Trans Ophthalmol Soc UK 1935;55:64.

2 Boughman JA, Vernon M, Shaver K. Usher syndrome: definition and estimate of prevalence from two high risk populations. F Chronic Dis 1983;36:595-603.

3 Smith RJH, Berlin CI, Hejtmancik JF, et al. Clinical diagnosis of Usher syndromes. Am $\mathcal{F}$ Med Genet 1994;50:32-8.

4 Weston MD, Kelly PM, Overbeck JD, et al. Myosin VIIA mutation screening in 189 Usher syndrome type 1 patients. Am 7 Hum Genet 1996;59:1074-83.

5 Kaplan J, Gerber S, Bonneau D, et al. Probable location of Usher type I gene on chromosome $14 \mathrm{q}$ by linkage with D14S13 (MLJ14 probe). Cytogenet Cell Genet 1991;58: 1988

6 Keats BJB, Nouri N, Pelias MZ, Deininger PL, Litt M. Tightly linked flanking microsatellite markers for the Usher syndrome type I locus on the short arm of chromosome 11. Am $\mathcal{F}$ Hum Gene 1994;54:681-6.

7 Wayne S, Der Kaloustian VM, Schloss M, et al. Localization of the Usher syndrome type 1D gene (USH1D) to chromosome 10. Hum Mol Genet 1996;10:1689-92.

8 Chaib H, Kaplan J, Gerber S, et al. A newly identified locus for Usher syndrome type 1, USH1E, maps to chromosom 21q21. Hum Mol Genet 1997;6:27-31.

9 Wayne S, Lowry RB, McLeod DR, Knaus R, Farr C, Smith RJH. Localization of the Usher syndrome type 1F (USH1F) to chromosome 10. Am f Hum Genet 1997;61: A300.

10 Kimberling WJ, Weston MD, Moller C, et al. Localization of Usher syndrome type II to chromosome 1q. Genomics 1990; 7:245-9.

11 Joensuu T, Blanco G, Pakarinen L, et al. Refined mapping of the Usher syndrome type III locus on chromosome 3, exclusion of candidate genes, and identification of the putative mouse homologous region. Genomics 1996;38: $255-63$.

12 Kimberling WJ, Weston MD, Moller C, et al. Gene mapping of Usher syndrome type IIa: localization of the gene to a 2.1-cM segment on chromosome 1q41. Am $\mathcal{f}$ Hum Genet 1995;56:216-23.

13 Sumegi J, Wang JY, Zhen DK, et al. The construction of yeast artificial chromosome (YAC) contig in the vicinity of the Usher syndrome type IIa (USH2A) gene in 1q41. Genomics 1996;35:79-86.

14 Pieke-Dahl S, van Aarem A, Dobin A, Cremers CWRJ, Kimberling WJ. Genetic heterogeneity of Usher syndrom type II in a Dutch population. $\mathcal{F}$ Med Genet 1996;33:753-7.

15 Gyapay G, Morissette J, Vignal A, et al. The 1993-94 Généthon human genetic linkage map. Nat Genet 1994;7:246339 